\title{
Behavioural Data in Credibility Assessment: Case Study of Kaja Godek's Explanatory Statement of Anti-LGBT Law*
}

\section{Behavioural Data in Credibility Assessment: Case Study of Kaja Godek's Explanatory Statement of Anti-LGBT Law}

\section{Abstract}

The paper explores the application of behavioural data analysis in the credibility assessment of a speaker. It presents how researchers investigate non-verbal communication, expressions of emotions or indicators of arousal to evaluate congruency using audiovisual material. Furthermore, the case study of Polish political activist Kaja Godek's explanatory statement of an anti-LGBT bill on October 28, 2021, suggests possible ways, in which the automated system FaceReader (and Facial Action Coding System as its theoretical background) may enrich methods of social science. As a result, it offers an example of an innovative approach towards political communication and the credibility of an argument.

Keywords: behavioural data analysis, credibility, political communication, Kaja Godek, FaceReader

* The paper is a result of the research project Role of emotions in an influence of remembrance narratives. Multi-level analysis financed from the funds of the National Science Center in Kraków, Poland, on the basis of the decision no. DEC-2016/21/B/HS5/00188. 


\section{Поведенческие данные в оценке достоверности: кейс-стади пояснительного заявления Каи Годек к закону о борьбе с ЛГБТ}

\section{Аннотация}

В статье исследуется применение анализа поведенческих данных для оценки достоверности говорящего. В ней показано, как исследователи исследуют невербальное общение, выражения эмоций или индикаторы возбуждения для оценки сооответсвия с использованием аудиовизуального материала. Более того, тематическое исследование пояснительного заявления польской политической активистки Каи Годек о законопроекте, направленном против ЛГБТ, от 28 октября 2021 года предлагает возможные решения, с помощью которых автоматизированная система FaceReader (и Система кодирования лица в качестве ее теоретической основы) может обогатить методы социальных наук. В результате статья является примером новаторского подхода к политической коммуникации и достоверности аргументации.

Ключевые слова: анализ поведенческих данных, достоверность, политическая коммуникация, Кая Годек, FaceReader

\section{Introduction}

cholars interested in political communication emphasise how important $\checkmark$ is construction, organisation and delivery of content. The expanding research on political narratives or mediatisation of politics proves that social scientists focus on story-telling and its proliferation among recipients. Political influence is deeply rooted in personal branding which is associated with credibility, authenticity and trustworthiness (Holly, 1989, p. 116). Public speakers are dependent on their perceived believability as a communicator to persuade an audience and impact its political preferences (O'Keefe, 1990, p. 130-131; Lord, Putrevu, 2009). Credibility is established as a result of judgements on one's trustworthiness and expertise it originates from attractiveness as a sincere and informed speaker (Gass, Seiter, 2004; Ohanian, 1991). Sungwook Hwang (2013, p. 254-256) associated politician's credibility with open-mindedness which implies a more dialogic form of communication and interactivity, as well as the construction of attractiveness as a function of sincere and reliable appearance. 
However, credibility assessment applies further than trustworthiness of narrative and authenticity of delivery. Recipients often tend to prefer general observations on speakers or gut-feeling about them over analysing specific behavioural cues - thus, the audience may not be aware of what shaped its judgments, yet it will assess one's credibility (Lim, Young, Brewer, 2021). The digitalisation of media with new possible communication channels and technological advancements simplified reaching audiences and flowing information, but it has not made all sources equally credible (Rotanova, 2021, p. 7). The relationship is rather opposite - extensive consumption of information accelerated by social media decreases credibility, which may even increase tendencies of not trusting fellow citizens (Karsen, Aalberg, 2021). Therefore, recipients (often unaware) search for indicators of honesty to separate reliable and unreliable sources. It expands the importance of behaviour assessment and non-verbal communication - even knowing that Albert Mehrabian overestimated the significance of facial channel in the overall impact of a message (Hegstrom, 1979; Mehrabian, Wiener, 1967; Mehrabian, Ferris, 1967), we agree that our cognition is oriented towards encoding facial expressions (Noah et al., 2020; Borod et al., 2002; Dailey et al., 2002; Jorna et al., 2021) and non-verbal messages mediate commitment towards communication (Asan et al., 2015).

Credibility requires congruent contents and behaviours. Expressions and gestures have to endorse arguments and opinions, particularly in the context of political persuasion and the speaker's believability. The common ground for verbal and non-verbal communication is an expression of emotions (Berry, Pennebaker, 1993; Weisbuch et al., 2010), which concurrently are a gateway to political preferences and decisions (Wawrzyński, 2015). Furthermore, the presence of emotions directly influences perceived credibility and shapes the recipient's judgements - as a result, the assessment of speaker's credibility is dependent on one's exposure to expressed emotions (Karduni et al., 2018, p. 19-21).

This paper aims at considering behavioural data analysis in the speaker's credibility assessment as an approach to understanding if consistent, verbal and non-verbal, communication may mediate perceived believability in politics. We discuss political activist Kaja Godek's explanatory statement on the anti-LGBT bill (\#StopLGBT initiative) delivered in Polish Sejm on October 
28,2021 . Ms Godek is a well-known, conservative canvasser and a leader of the pro-life movement in Poland, yet surprisingly she promoted a radical initiative against LGBT rights. The bill resembles Russian authoritarian legislations which repress all kinds of LGBT activism and institutionalise homophobia as a part of state's ideology (Wilkinson, 2014; Buyantueva, 2018; Suchland, 2018) what raises further concerns in the context of democratic backsliding in Poland (Skrzypek, 2021, p. 40). Therefore, the paper investigates the question of whether Ms Godek is genuinely dedicated to limiting LGBT rights in Poland or rather she exploits the initiative to hog the right-wing limelight as her anti-abortion movement dispersed after the Constitutional Court's ruling in October 2020 (Koralewska, Zielińska, 2021).

\section{Method}

In the case study, we use the automated system FaceReader 8.1 developed by Noldus Information Technology, the high accuracy software for classification emotional expressions (den Uyl, van Kuilenburg, 2005). Automated facial coding system exploits Facial Action Coding System (FACS), the major reference manual for manual facial coding (Ekman, Friesen, Hager, 2002). Both FACS and FaceReader explore the theory of basic emotions, assuming the universality of facial expressions of sadness, anger, disgust, contempt, fear, surprise and happiness (Ekman, 1992; 1999; Rosenberg, Ekman, 1995). Peter Lewinsky and his associates (2014, p. 235) concluded in their evaluation: "we believe that FaceReader has proven to be a reliable indicator of facial expressions of basic emotions in the past decade and has the potential to become similarly robust with FACS coding. [...] Further, FaceReader categorization of basic emotions is reliable and does not need human correction". However, the application of the system is limited because of technological requirements listed by Tanja Skiendziel, Andreas G. Rösch and Oliver C. Schultheiss (2019): high-resolution video file, restrained body movements and portrait shots, that establish optimal conditions for FaceReader analysis.

Chia-Yin Yu and Chih-Hsiang Ko (2017) claimed that the system is not only a precise tool to detect emotional expression but the results of its coding are corroborated by the verbal behaviour of participants. Furthermore, the application of FaceReader in research offers more than automated facial 
coding of basic emotions with reference to FACS. It offers additional algorithms to analyse emotional arousal and valence, as well as dimensional behaviours (Hadinejad et al., 2018, p. 2). The 8.1 software version used in this case study offers estimated heart rate charts thanks to (Remote Photoplethysmography Module's) algorithms analysing major arteries around the face. In total, we can measure emotional expressions, arousal and valence, head orientation and estimated heart rate, as well as code basic action units and facial states. FaceReader offers us results as timelines and charts detailed to $1 / 10$ second and exported behavioural data detailed to $1 / 25$ second.

The case study investigates the audio-visual recording of Kaja Godek explanatory statement of October 28, 2021, in Polish Sejm. The file was downloaded from YouTube's account of Ms Godek's organisation - Fundacja Życie i Rodzina. It lasts 7 minutes and 24 seconds, yet the first three and the last four seconds do not offer the necessary framing of a take, thus we were able to analyse the remaining 7 minutes and 17 seconds of the speech. Contents analysis enabled us to limit our interest to paramount eleven parts of the statement, which left us with 4 minutes and 22 seconds of core verbal and non-verbal performance when Ms Godek attempted to justify the bill and extreme limitations of LGBT rights.

Firstly, we had to elucidate the argument presented in the speech. Ms Godek in her narrative exploited the following issues: a clash between traditional values and leftist anti-values, LGBT violence against conservatives, ideological attacks on the family as a foundation of social structure, abuse of children and paedophilia, suicides of non-heteronormative teenagers, treatment of homosexuals and homosexual propaganda. In fact, her argument followed and imitated Russian official anti-LGBT cliches adopted by Polish right-wingers in the last years (Wróbel, 2019; Persson, 2015; Khlusova, 2017). In the conclusion, she clearly expressed that considers LGBT activism and its claims as a disgusting attempt to abuse children and harness them in political conflict (Godek, 2021).

Content analysis established a framework of Ms Godek's understanding of the non-heteronormativity as a (treatable) disfunction and a real menace to youth (alongside alcohol and drugs abuse). In this context, what are we expected to discover in behavioural analysis? It was safe to predict that the statement should be powered by contempt towards LGBT activists, disgust 
towards non-heteronormative sexual practices and anger inspired by attempts to reshape traditional social order based on conservative values and heterosexual families. In addition, these three principal emotions might be supplemented by fear of unpredictable results of LGBT activism or sadness caused by the sense of loss. Finally, positive emotions should be limited to imaginations of conservative order, which in the introduction Ms Godek constructed around the protection of human life since conception, central position of the family, the sanctity of private property and individual freedoms. We assumed that she should be most engaged and aroused while arguing that LGBT activism harms children and its supporters are responsible for suicides among troubled teenagers - as that were emotional peaks of the narrative. These four hypotheses we addressed in our behavioural data analysis.

\section{Results}

In the analysed sample we observed 90 significant, stronger than subtle emotional expressions, from which 60 was labelled as slight and 30 as medium - nine times they exceeded 0.5 level, yet never reached 0.7 level for strong expressions. On average, we noticed 0.34 units per second, while one for ten seconds arousal peaked at medium level. It offers us a baseline to discuss non-verbal behaviour in selected parts of Ms Godek's speech.

Presence and distribution of emotional expressions is presented in the Table 1. Collected data showed the dominance of anger - almost $70 \%$ of all expressions and more than $90 \%$ of medium-level units represented Ms Godek's wrath. For remaining observations, half covered other negative emotions and half non-negative states. Moreover, happiness, fear and disgust were marginal, while contempt was not present at all. Surprise sprung up from time to time, mostly when she oriented herself towards left-wing members of parliament in the chambers. Sadness supplemented anger and it played a key role only when Ms Godek imagined her conversation with child about "discovering homosexual preferences" (5’30"-5’36"). 
Table 1. Presence of emotional expressions in Kaja Godek's explanatory statement (medium for expression stronger than 0.3, slight for stronger than 0.1 and weaker than 0.3, see: Ekman, Friesen \& Hager, 2002)

\begin{tabular}{|c|c|c|c|c|c|c|c|c|c|c|c|c|c|c|}
\hline & \multicolumn{2}{|c|}{ Contempt } & \multicolumn{2}{|c|}{ Disgust } & \multicolumn{2}{|c|}{ Anger } & \multicolumn{2}{|c|}{ Sadness } & \multicolumn{2}{|c|}{ Fear } & \multicolumn{2}{|c|}{ Surprise } & \multicolumn{2}{|c|}{ Happiness } \\
\hline & $\begin{array}{l}\overrightarrow{\overrightarrow{0}} \\
\bar{*} \\
\bar{\omega}\end{array}$ & 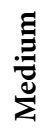 & $\begin{array}{l}\overrightarrow{E_{0}} \\
\frac{\mathrm{w}}{\omega}\end{array}$ & 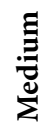 & $\begin{array}{l}\frac{\overrightarrow{7}}{50} \\
\frac{\pi}{5}\end{array}$ & 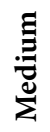 & $\begin{array}{l}\overrightarrow{\overline{5}} \\
\frac{.00}{\omega}\end{array}$ & 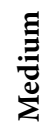 & $\begin{array}{l}\vec{\Xi} \\
\frac{.0}{\omega}\end{array}$ & 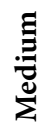 & $\begin{array}{l}\frac{\overrightarrow{5}}{500} \\
\frac{\pi}{\omega}\end{array}$ & 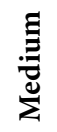 & $\begin{array}{l}\frac{\vec{E}}{60} \\
\frac{\#}{\omega}\end{array}$ & 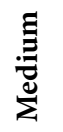 \\
\hline $\begin{array}{l}0: 40- \\
1: 05\end{array}$ & & & & & 4 & 1 & 1 & & 1 & & & & 2 & \\
\hline $\begin{array}{l}1: 18- \\
1: 58\end{array}$ & & & 1 & & 5 & 1 & 1 & & & & 1 & & 1 & \\
\hline $\begin{array}{l}2: 15- \\
2: 35\end{array}$ & & & & & 3 & & 1 & & & & 2 & & & \\
\hline $\begin{array}{l}2: 55- \\
3: 32\end{array}$ & & & & & 1 & 1 & & & & & 2 & & & \\
\hline $\begin{array}{l}3: 50- \\
4: 00\end{array}$ & & & & & 2 & 4 & & & & & & & & \\
\hline $\begin{array}{l}4: 20- \\
4: 30\end{array}$ & & & & & 1 & & 3 & & & & & & & \\
\hline $\begin{array}{l}4: 35- \\
5: 00\end{array}$ & & & & & 2 & 2 & & & 1 & & 1 & & 1 & \\
\hline $\begin{array}{l}5: 03- \\
5: 18\end{array}$ & & & & & 3 & 2 & & & 1 & & 2 & & 1 & \\
\hline $\begin{array}{l}5: 23- \\
5: 45\end{array}$ & & & & & 5 & 6 & & 2 & 1 & & & & & \\
\hline $\begin{array}{l}\text { 6:05- } \\
6: 50\end{array}$ & & & 1 & & 5 & 7 & & & 1 & & 1 & & & \\
\hline $\begin{array}{l}7: 05- \\
7: 18\end{array}$ & & & & & 2 & 4 & & & & & & & & \\
\hline Total & 0 & $\mathbf{0}$ & 2 & 0 & 33 & 28 & 6 & 2 & 5 & 0 & 9 & $\mathbf{0}$ & 5 & 0 \\
\hline
\end{tabular}

The most emotional part of the statement ( $\left.5^{\prime} 23^{\prime \prime}-5^{\prime} 45^{\prime \prime}\right)$ includes a presentation on non-heteronormativity as the menace to youth - for 15 of 22 seconds anger is at least subtle, peaking at 0.6 level when she names homosexuality as "something harming child's development". As mentioned above, two significant expressions of sadness appear when Ms Godek wondered about the possible coming-out of her child (Image 2) - we believe that it should be considered as genuine microexpressions leaking authentic feelings towards this scenario. When brief, one-second-long sorrow manifested on 
her face, wrath was suppressed, yet her narrative did not reflect that empathetic response to a fantasy.

The second most emotional section was Ms Godek's story on LGBT violence against her colleagues campaigning for the anti-LGBT bill and promoting conservative values (3'50"-4'00"). The argument was associated with progressing rage which peaked in a furious expression when she considers those actions as a crime (Image 1). In general, quite emotional is also a part where she accused LGBT activists of being responsible for suicides of non-heteronormative teenagers ( $\left.5^{\prime} 03^{\prime \prime}-5^{\prime} 18^{\prime \prime}\right)$, however, it was dominated by slight expressions of anger and surprise when she addressed the left-wing audience. Some stronger representations of wrath appeared in the conclusion when Ms Godek considered actions of LGBT activists as disgusting $\left(7^{\prime} 05^{\prime \prime}-7^{\prime} 18\right.$ ') - quite surprisingly that indicative statement was lacking any signs of disgust or contempt. Moreover, contempt is absent during whole speech, while slight expressions of disgust briefly appear discussing leftist anti-values (1'33") and underestimation of right-wingers' concerns (6'17').

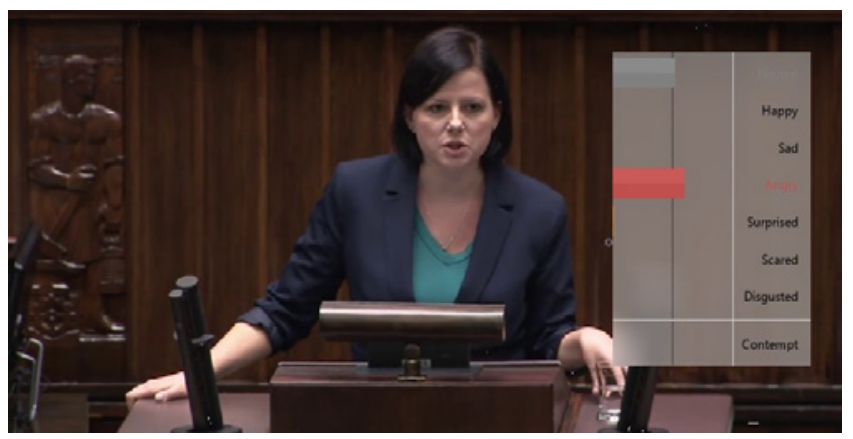

Image 1. Medium expression of anger in Kaja Godek's statement (3'57") while discussing LGBT violence against conservative campaigners (FaceReader 8.1).

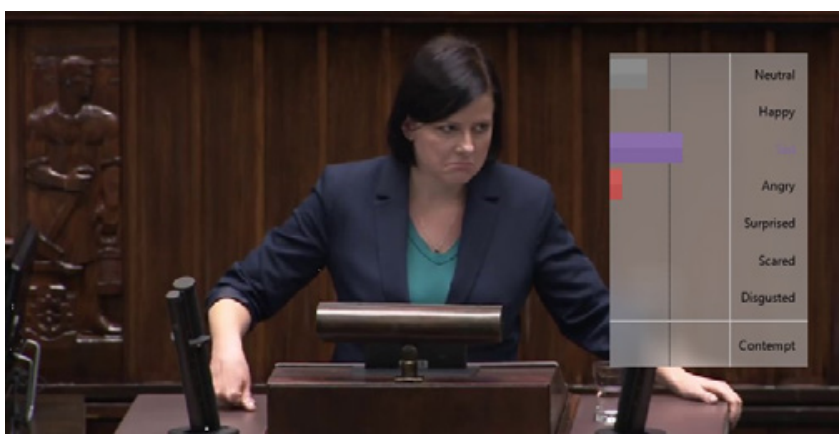

Image 2. Medium expression of sadness in Kaja Godek's statement (5'31") while imagining response to non-heteronormative child's coming-out (FaceReader 8.1). 
Even the most subtle signs of disgust are present through 68 seconds of her statement, which means that even the slightest level of this emotion was present during less than $1 / 5$ of the speech - peaking when addressing police violence against conservative protesters, instead of any of numerous verbal attacks on sexual minorities.

In general, the first part of Kaja Godek's speech is less emotional in non-verbal channels. While her argument is intense, and her rhetoric is close to hate speech, facial expressions are occasional and rather subtle. During the opening three and half minutes, only five seconds include medium-level units with brief representations of anger - moreover, for long sections, there is no even slight expression of any emotion. At the same time, she criticised leftist ideology and LGBT activism, discussed the framework of a cultural clash between homosexual propaganda and conservative values, associated paedophilia with non-heteronormativity and claimed that LGBT persons should be excluded from education and child care. Not until her story on leftist violence against conservative campaigners, Ms Godek seemed to be emotionally distant from the presented argument. The same observations apply for ending allegations of the destructive impact of homosexual propaganda on children, youth and families - however, this part is more filled with returning brief expressions of anger, especially when she explores the idea that her adversaries are guided by a rule "the more gay people, the better" (6'09").

Arousal. The first half of Kaja Godek's statement did not deeply engage her, most of it represented arousal below a baseline (0.3) - only discussing cases of leftist violence against conservative activists she expressed more interest in her emotional communication. A very low level of arousal accompanied her imagined conversation with the coming-out child what corresponds with much higher engagement $(0.4)$ while explaining strategies of pro-LGBT indoctrination of youth just 20 seconds later. Higher arousal is present in the most emotional section of the speech (5'23"-5'45") when it twice reaches medium level. For the last time, it significantly exceeded the baseline when describing how sexual education has increased the share of non-heteronormative youth in New York (6'20").

Even more important is that the arousal chart was flat when Ms Godek verbally expressed her concerns and attacked LGBT activists for destructive 
influence on society. We assumed that when accusing someone of being responsible for suicide of teenagers, the speaker should experience somehow higher emotional arousal - as a result, in the case of Ms Godek non-verbal signals did not supported shared opinions. Same observations are applicable to her radical statement on links between non-heteronormativity and paedophilia or pretended disgust towards LGBT people in concluding remarks. There is no behavioural evidence to support the hypothesis that Ms Godek was engaged in delivery of her strong anti-LGBT message, especially when we compare her non-verbal signals with contents of the speech.

Stress. There were two major stressful events during Kaja Godek's explanatory statement that were indicated by data collected by FaceReader's RPPG module. The estimated hearth rate exceeded $100 \mathrm{bpm}$ for 16 seconds between 6'15" and 6'31" when she criticised underestimating conservative concern about impact of sexual education and LGBT activism on youth and their sexual orientation. Shortly after that, she experienced stress for other 24 seconds between 6'42" and 7'06" when Ms Godek developed the issue and stated that protection of minorities is used as a facade to conceal true objectives of leftist activists. In both cases the increase of hearth rate corresponded with recurring medium expressions of anger and quite limited other emotional arousal, despite one slight expression of fear in the first excerpt.

For most of the speech, the estimated heart rate indicated calmness and neutrality as it ranged between 50 and $65 \mathrm{bpm}$. During the first six minutes of the statement, it exceeded $80 \mathrm{bpm}$ just for 22 seconds, while in ending 78 seconds this physiological excitement covered $87 \%$ of the time. Interestingly, Ms Godek calmed down when naming LGBT activism disgusting, which also was her closing argument in the debate. It is noticeable that the presentation of arguments why the limitation of LGBT rights will serve the public good was for her very stressful experience, yet we are not able to determine what caused the excitement and what for this response was activated by the sympathetic nervous system. Considering the complexity of collected behavioural data, it is justified to assume that she was stressed because of her lack of expertise in the field and authenticity in a promoted argument. In fact, she might be aware that her credibility was contested and she felt that radical and indicative statements did not provoke more sincere engagement. 


\section{Discussion}

The application of automated analysis of behavioural data opens new possibilities for research on political communication and persuasion. In the case of Kaja Godek's explanatory statement in Polish Sejm, we stated four hypotheses that correspond with collected data. The speech was dominated by anger, however, it was directed rather towards leftist activists than LGBT people - of course, Ms Godek was outraged when discussing attacks on social order, conservative values and traditional families, but she expressed neither contempt nor disgust towards non-heteronormative individuals. The wrath was more general, she is disappointed with modern society and she has an aggressive attitude towards the world. However, it is hard to assume that she believed in her argument as she did not seem to be (emotionally) committed to anti-LGBT postulates. Ms Godek's narrative and emotional behaviour were highly inconsistent - she presented trivial troubles of conservative activists with sincere rage, yet was rather empathetic imagining her child's coming-out and emotionally distanced when attacking the LGBT movement as responsible for suicides of teenagers struggling with their sexual identity or orientation. Clearly, she was angrier when describing police examination of her colleague than portraying homosexuals as children abusers, paedophiles and the menace alike psychoactive substances abuse - line charts of exemplary samples are presented in Graphs 1,2 and 3.

Moreover, the incongruency of anger, disgust and contempt is not the sole issue of Ms Godek's statement when comparing behavioural data with a narrative. Fear was present randomly and it was not associated with results of LGBT activism, sadness was less about dealing with loss and more about compassionate response towards parents of non-heteronormative children. It is not clear if Ms Godek emphasises LGBT people, but she seems to understand how hard it may be for their family to deal with this challenge (see Graph 2). Microexpressions of sadness appeared when discussing if homosexuality can be treated like maladaptive coping strategies what again contradicted the radical rhetoric of her speech.

During the statement, we were able to observe only five slight expressions of happiness. This emotion was even less important than disgust and in the most subtle form, it was present during 67 seconds of analysed recording. For 


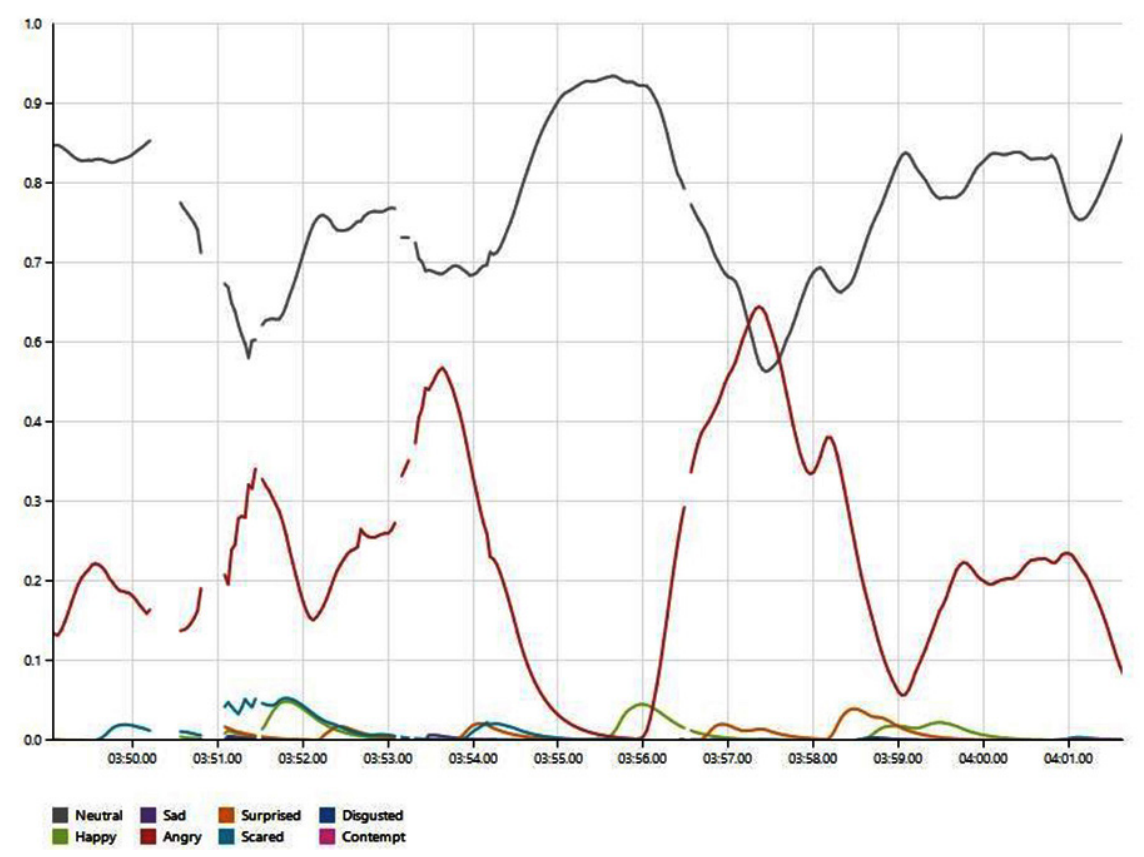

Graph 1. Expression Line Chart: 3'49"-4'02" while Kaja Godek presented leftist violence against conservative campaigners (FaceReader 8.1).

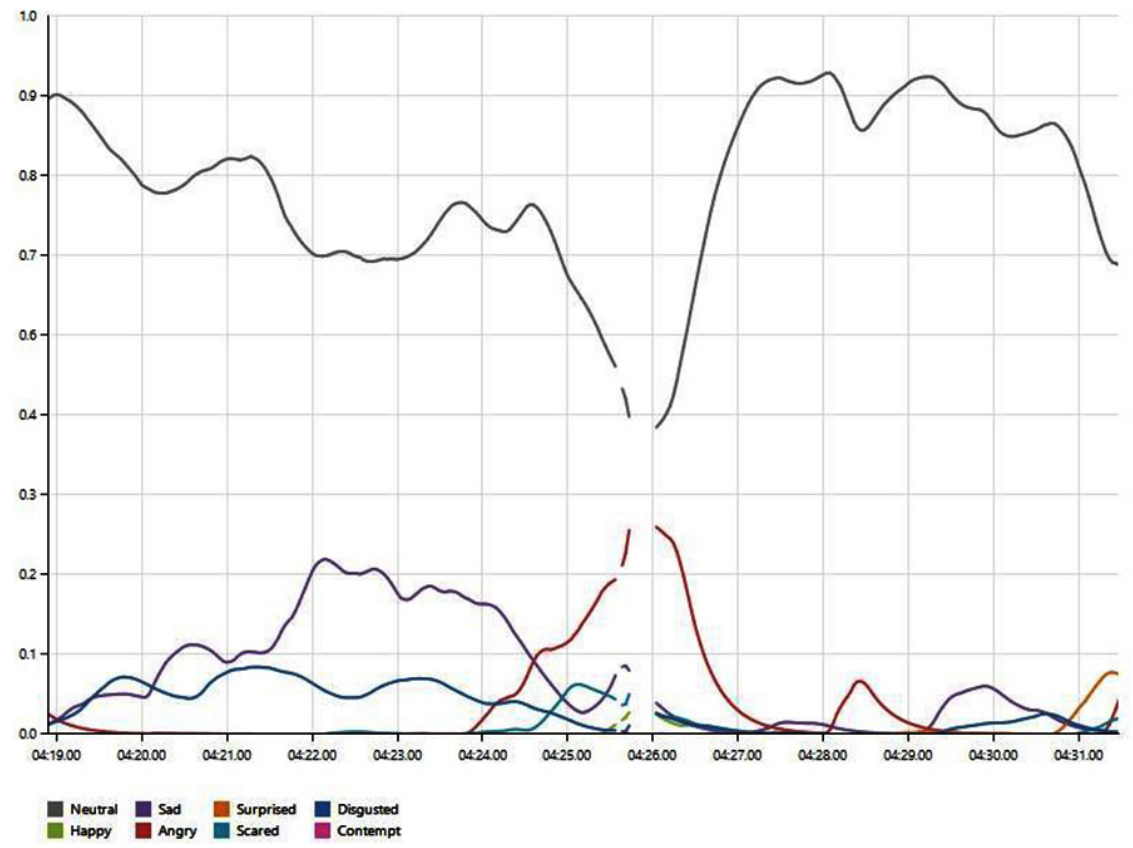

Graph 2. Expression Line Chart: 4'19"-4'32" while Kaja Godek explored imagined conversation with coming-out non-heteronormative child (FaceReader 8.1). 


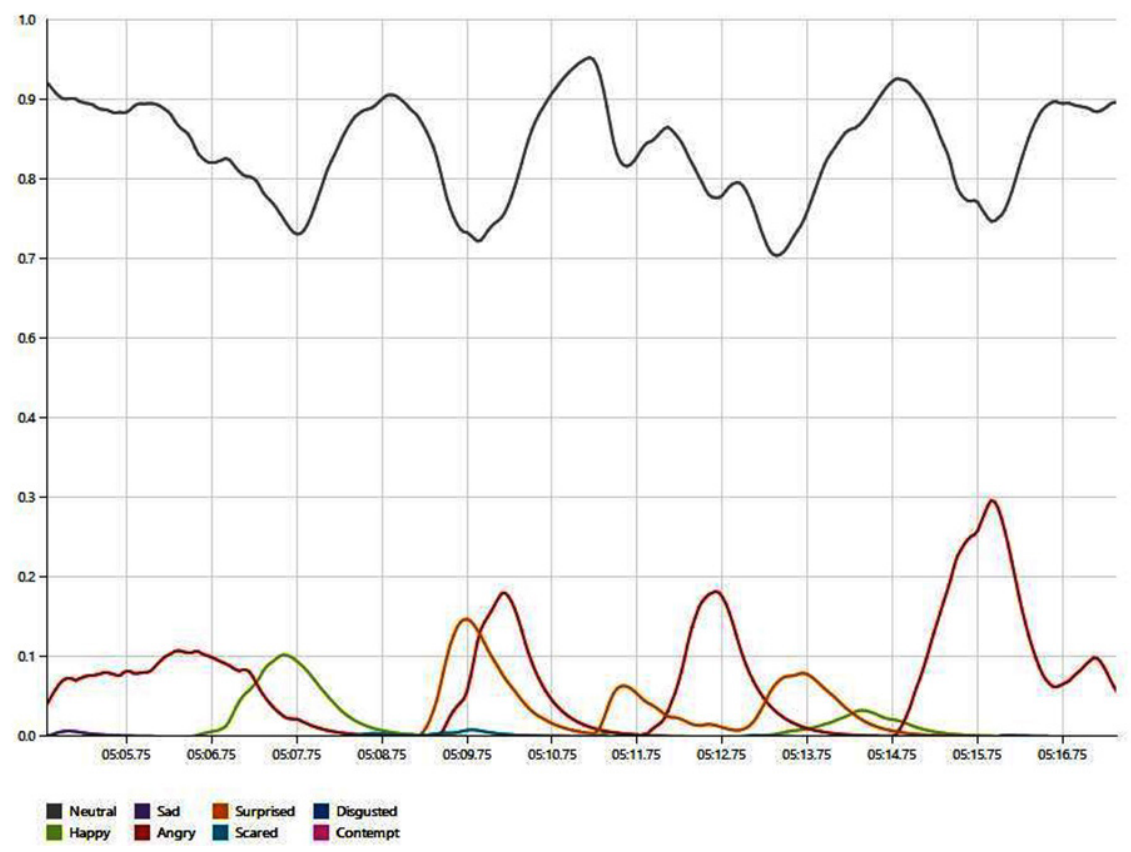

Graph 3. Expression Line Chart: 5'04'-5'17' while Kaja Godek accused LGBT activists as being responsible for suicides of troubled teenagers (FaceReader 8.1).

the first time, a slight signal of positive emotions appears when Ms Godek compared traditional values to leftist anti-values ( $0^{\prime} 45^{\prime \prime}$ and 1'39"), then it was noticeable while she criticises left-wing MPs for absence during the debate (1'10"). Other brief expressions of happiness were identified when she speculated about paying teenagers to participate in pro-LGBT events (4'55") and during her comparison of non-heteronormativity to substance abuse (5'59"). Twice our observations supported the prediction, yet in the other three cases presence of happiness was unrelated to Ms Godek's imagination of conservative order, which can be considered as a result of her lack of (emotional) commitment towards the proclaimed vision. Moreover, we can assume that she simply enjoyed confrontation with her leftist adversaries and for Ms Godek campaigning for anti-LGBT law was a kind of vengeance on left-wing activists who attacked her pro-life initiatives. 
Finally, as we noticed before behavioural analysis does not deliver evidence that Ms Godek was more engaged and aroused while presenting her radical argument against the LGBT movement and exploiting rhetoric close to hate speech. The arousal line for her statement is rather flat and close to the baseline - its peaks do not correspond with narrative culminations. We may interpret it in two ways: firstly, as proof of Ms Godek's faint communicative skills and secondly, as an argument against her credibility. The further interpretation is supported by estimated heart rate variability - she was more nervous when she had to present detailed reasons why Polish society will benefit from restricting LGBT rights. Her behaviour suggests limited authenticity and stressful response to her own lack of expertise in the field - it is corroborated by the presence of lapses and verbal slips in her speech and misunderstanding of relevant categories in her argument.

\section{Conclusion}

My recent research report (Wawrzyński, 2021) addressed the issue of how to apply behavioural data analysis in credibility assessment in the context of imitated expressions of emotions. In this case study of political activist Kaja Godek's explanatory statement of the anti-LGBT bill, we considered incongruency and inadequacy of a narrative and non-verbal signalling. The application of the FaceReader automated coding system offered us a detailed and accurate review of all facial actions and states presented during the speech. The comparison of contents and behavioural data allowed us to verify predictions and to conclude that Ms Godek's involvement in the anti-LGBT initiative was rather an example of attention-seeking behaviour (Dawson, 1985; Mellor, 2005) than a result of her beliefs. She enjoyed confrontation with her adversaries and exploited an opportunity to express her aggressive attitude towards modern society, but she did not present signs of genuine aversion to LGBT people.

Therefore, regarding behavioural data analysis and its comparison to results of content analysis, it is impossible to assess Kaja Godek as credible. Her emotional behaviour was inconsistent with the presented narrative, her arousal was different than the dynamics of an argument, and stressful responses suggested her awareness of the lack of expertise. Neutral recipients 
would not perceive her as a believable source of knowledge, while her persuasion would be ineffective - her argument might be interesting only for recipients in favour of restricting LGBT rights, but not because of compelling rhetoric or delivery, but simply because of confirmation bias (Klayman 1995). However, even the construction of speech limited its trustworthiness and persuasive capability, as more than twenty years ago Jay A. Conger (1998: 87) emphasised: "Persuasion, in other words, often involves indeed, demands - compromise. Perhaps that is why the most effective persuaders seem to share a common trait: they are open-minded, never dogmatic. They enter the persuasion process prepared to adjust their viewpoints and incorporate others' ideas. That approach to persuasion is, interestingly, highly persuasive in itself".

The presented case study showed how behavioural data analysis can be adopted in social sciences, especially considering political communication and persuasion. The delivered assessment of Kaja Godek's credibility and trustworthiness of her argument in favour of radical anti-LGBT laws in Poland explored these possibilities and it offers valuable insight into possible motivations of far-right activists in the context of Poland's democratic backslide.

\section{DR PATRYK WAWRZYŃSKI}

Nicolaus Copernicus University

Alpaka Innovations

ul. Grudziądzka 91, 87-100 Toruń

p.wawrzynski@alpakainnovations.com

\section{References}

Asan, O., Young, H.N., Chewning, B., Montague, E. (2015). How physician electronic health record screen sharing affects patient and doctor non-verbal communication in primary care. Patient Education and Counseling 98(3), 310-316. DOI: 10.1016/j. pec.2014.11.024.

Berry, D.S., Pennebaker, J.W. (1993). Nonverbal and Verbal Emotional Expression and Health. Psychotherapy and Psychosomatics, 59, 11-19. DOI: 10.1159/000288640. 
Borod, J.C., Bloom, R.L., Brickman, A.M., Nakhutina, L., Curko, E.A. (2002). Emotional Processing Deficits in Individuals With Unilateral Brain Damage. Applied Neuropsychology, 9(1), 23-36. DOI: 10.1207/S15324826AN0901_4.

Buyantueva, R. (2018). LGBT Rights Activism and Homophobia in Russia. Journal of Homosexuality, 65(4), 456-483. DOI: 10.1080/00918369.2017.1320167.

Chia-Yin Yu, Chih-Hsiang Ko (2017). Applying FaceReader to Recognize Consumer Emotions in Graphic Styles. Procedia CIRP, 60, 104-109. DOI: 10.1016/j. procir.2017.01.014.

Conger, J.A. (1998). The Necessary Art of Persuasion. Harvard Business Review (MayJune), 84-95.

Dailey, M.N., Cottrell, G.W., Padgett, C., Adolphs, R. (2002). EMPATH: A Neural Network that Categorizes Facial Expressions. Journal of Cognitive Neuroscience 14(8), 1158-1173. DOI: 10.1162/089892902760807177.

Dawson R.L. (1985) Attention Seeking Behaviour. In: R.L. Dawson (ed.), Teacher Information Pack 1: Behaviour (33-40). London: Palgrave. DOI: 10.1007/978-1-349-08997-0_3.

Ekman, P. (1992). Are There Basic Emotions? Psychological Review, 99(3), 550-553.

Ekman, P. (1999). Basic emotions. In: T. Dalgleish, M.J. Power (eds.). Handbook of cognition and emotion (45-60). New York: Wiley.

Ekman, P., Friesen, W.V., Hager, J.C. (2002). Facial Action Coding System: The Manual on CD ROM. Salt Lake City: Research Nexus.

Gass, R.H., Seiter, J.S. (2004). Persuasion, social influence, and compliance gaining. Boston: Pearson.

Godek, K. (2021, October 28). Kaja Godek przemawia podczas debaty o ustawie \#StopLGBT w Sejmie. Accessed: https://www.youtube.com/watch?v=7R1b9SOT-MU.

Hadinejad, A., Moyle, B.D., Scott, N., Kralj, A. (2019). Emotional responses to tourism advertisements: the application of FaceReader ${ }^{\text {Tw. }}$. Tourism Recreation Research, 44(1), 131-135. DOI: 10.1080/02508281.2018.1505228.

Hegstrom, T.G. (1979) Message impact: What percentage is nonverbal? Western Journal of Speech Communication, 43(2), 134-142, DOI: 10.1080/10570317909373961.

Holly, W. (1989). Credibility and Political Language. In: R. Wodak (ed.). Language, Power and Ideology: Studies in Political Discourse (115-136). Amsterdam-Philadelphia: John Benjamins Publishing Company.

Jorna, L., Westerhof-Evers, H., Khosdelazad, S., Rakers, S., Van der Naalt, J., Groen, R., Bunk, A.M., Spikman, J. (2021). Behaviors of Concern after Acquired Brain Injury: The Role of Negative Emotion Recognition and Anger Misattribution. Journal of the International Neuropsychological Society. DOI: 10.1017/S135561772000140X.

Karduni, A., Wesslen, R., Markant, D., Wenwen Dou (2018). Images, Emotions, and Credibility: Effect of Emotional Facial Images on Perceptions of News Content Bias and Source Credibility in Social Media. ArXiv: Cornell University. DOI: 10.1145/1122445.1122456.

Karlsen, R., Aalberg, T. (2021). Social Media and Trust in News: An Experimental Study of the Effect of Facebook on News Story Credibility. Digital Journalism. DOI: $10.1080 / 21670811.2021 .1945938$. 
Khlusova A. (2017). Legitimising Political Homophobia: Sexual Minorities and Russian Television News. In: R. Sanz Sabido (ed.). Representing Communities: Discourse And Contexts(97-116).London:Palgrave Macmillan.DOI:10.1007/978-3-319-65030-2_6.

Klayman, J. (1995). Varieties of Confirmation Bias. In: J. Busemeyer, R. Hastie, DL. Medin (eds.). Psychology of Learning and Motivation (385-418). Cambridge: Academic Press. DOI: 10.1016/S0079-7421(08)60315-1.

Koralewska, I., Zielińska, K. (2021). 'Defending the unborn', 'protecting women' and 'preserving culture and nation': anti-abortion discourse in the Polish right-wing press. Culture, Health \& Sexuality. DOI: 10.1080/13691058.2021.1878559.

Lewinski, P., den Uyl, T.M., Butler, C. (2014). Automated facial coding: Validation of basic emotions and FACS AUs in FaceReader. Journal of Neuroscience, Psychology, and Economics, 7(4), 227-236. DOI: 10.1037/npe0000028.

Lim, A., Young, R.L., Brewer, N. (2021) Autistic Adults May Be Erroneously Perceived as Deceptive and Lacking Credibility. Journal of Autism and Developmental Disorders. DOI: 10.1007/s10803-021-04963-4.

Lord, K.R., Putrevu, S. (2009). Informational and transformational responses to celebrity endorsements. Journal of Current Issues and Research in Advertising, 31, 1-13.

Mehrabian, A., Ferris, S.R. (1967). Inference of Attitudes from Nonverbal Communication in Two Channels. Journal of Consulting Psychology, 31, 248-252.

Mehrabian, A., Wiener, M. (1967). Decoding of Inconsistent Communications. Journal of Personality and Social Psychology, 6, 109-114.

Mellor, N. (2005). Attention seeking: The paradoxes of an under-researched concept. Educational \& Child Psychology, 22(4), 94-107.

Noah, J.A., Zhang, X., Dravida, S., Ono, Y., Naples, A., McPartland, J.C., Hirsch, J. (2020). Real-Time Eye-to-Eye Contact Is Associated With Cross-Brain Neural Coupling in Angular Gyrus. Frontiers in Human Neuroscience, 14(19). DOI: 10.3389/ fnhum.2020.00019.

Ohanian, R. (1991). The impact of celebrity spokespersons' image on consumers' intention to purchase. Journal of Advertising Research, 31, 46-54.

O'Keefe, D. J. (1990). Persuasion: Theory and research. Newbury Park: Sage.

Persson, E. (2015). Banning "Homosexual Propaganda": Belonging and Visibility in Contemporary Russian Media. Sexuality \& Culture, 19, 256-274. DOI: 10.1007/ s12119-014-9254-1.

Rosenberg, E.L., Ekman, P. (1995). Conceptual and Methodological Issues in the Judgement of Facial Expressions of Emotion. Motivation and Emotion, 19(2), 111-138.

Rotanova, M.B. (2021). A New Digital Landscape and Politicians' Public Performance Evaluation. 2021 Communication Strategies in Digital Society Seminar (ComSDS), St. Peterburg: IEEE. DOI: 10.1109/ComSDS52473.2021.9422874.

Skiendziel, T., Rösch, A.G., Schultheiss, O.C. (2019). Assessing the convergent validity between the automated emotion recognition software Noldus FaceReader 7 and Facial Action Coding System Scoring. PLOS ONE 14(10). DOI: 10.1371/journal. pone.0223905.

Skrzypek, M. (2021). Democratic Backsliding in Poland on Example Drafts Amendments in Electoral Code During the COVID-19 Pandemic. Polish Political Science Yearbook, 50(2), 37-50. DOI: 10.15804/ppsy202103. 
Suchland, J. (2018). The LGBT specter in Russia: refusing queerness, claiming 'Whiteness'. Gender, Place \& Culture, 25(7), 1073-1088. DOI: 10.1080/0966369X.2018.1456408.

Sungwook Hwang (2013). The Effect of Twitter Use on Politicians' Credibility and Attitudes toward Politicians. Journal of Public Relations Research, 25(3), 246-258. DOI: 10.1080/1062726X.2013.788445.

Den Uyl, M.J., van Kuilenburg, H. (2005). The FaceReader: Online facial expression recognition. In: L. Noldus, F. Grieco, L. Loijens, P.H. Zimmerman (eds.). Proceedings of Measuring Behavior 2005: 5th International Conference on Methods and Techniques in Behavioral Research (589 - 590). Wageningen: Noldus Information Technologies.

Wawrzyński, P. (2015). Emocje i zaangażowania a skuteczność narracji polityki historycznej. Wyniki badań eksperymentalnych. Pamięć i Sprawiedliwość, 26, 159-181.

Wawrzyński, P. (2021). Czy łzy Beaty Kempy były szczere? Accessed: https://alpakainnovations.com/2021/10/22/czy-lzy-beaty-kempy-byly-szczere/.

Weisbuch,M.,Ambady, N., Clarke,A.L.,Achor, S., Veenstra-Vander Weele, J.(2010).On Being Consistent: The Role of Verbal-Nonverbal Consistency in First Impressions. Basic and Applied Social Psychology, 32(3), 261-268. DOI: 10.1080/01973533.2010.495659.

Wilkinson, C. (2014). Putting “Traditional Values” Into Practice: The Rise and Contestation of Anti-Homopropaganda Laws in Russia. Journal of Human Rights, 13(3). 363-379. DOI: 10.1080/14754835.2014.919218.

Wróbel, M. (2019). The images of "Rainbow Friday" in liberal and conservative online media. Polish Journal of Political Science, 5(4), 27-58. 